\title{
Vida cotidiana con sabor a poco
}

\section{Escenas de la vida cotidiana: Uruguay 1950-1973, sombras sobre el país modelo.}

\section{TROCHON, Yvette.}

Montevideo: Ediciones de la Banda Oriental, $2011.383 \mathrm{p}$.

La historiadora Yvette Trochon escribe el libro titulado: Escenas de la vida cotidiana, Montevideo, Ediciones de la Banda Oriental, 2011. Ésta editorial viene publicando una serie de libros que intentan acercar aspectos de la historia del Uruguay que pocos historiadores han apreciado. En este caso, el tomo tercero fue llamado "Sobras sobre el país modelo" que corresponde al período de 1950-1973.

La autora nació en Montevideo en 1943, es profesora de Historia egresada del Instituto de Profesores Artigas. Durante su carrera docente impartió clases en Enseñanza Secundaria y dentro del mismo instituto donde se formó. Ha publicado una gran cantidad de títulos entre los que se destacan: Baldomir y la restauración democrá- tica (1938-1946) (1987); El régimen terrista. Aspectos políticos, económicos y sociales (1933-1938) (1993), todos en colaboración. Mientras que de su sola autoría podemos mencionar: Las mercenarias del amor. Prostitución y modernidad en el Uruguay. (1880-1932) (2003); Las rutas de Eros. La trata de blancas en el Atlántico Sur. Argentina, Brasil y Uruguay. (18801932) (2006); y Cosecha de sangre. Crímenes que conmovieron al Uruguay del siglo XX (2008).

Este libro se lo puede enmarcar historiográficamente dentro de la llamada historia de la vida privada, género que supo introducir en nuestro país el historiador José Pedro Barrán. La vida cotidiana que intenta estudiar Trochon estaría orientada a destacar la forma de vida de aquellas personas "anónimas" que poblaron nuestro país, y que la historia tradicional, más adepta a las estructuras políticas, económicas y sociales, llegó a desestimar.

Respecto a su última publicación, si bien observamos que los cortes cronológicos en todos los casos son propuestos por los historiadores en forma subjetiva, en esta oportunidad podemos claramente entrever el por qué de la elección. Por un lado tenemos 1950, año de la famosa gesta de Maracaná, donde el Uruguay se mostraba como un pequeño país victorioso, democrático, culto y modélico, frente al resto 
del mundo, de allí se deprendería el famoso epíteto de "la Suiza de América". En cambio 1973 sería el año marcado por el golpe de Estado de Juan María Bordaberry, el comienzo de la dictadura en un país inmerso en la crisis económica, política y social, que daría comienzo a una nueva época.

Generalmente se ha afirmado que la década del '50 estaría signada por la bonanza y el optimismo generalizado, mientras que en la del '60 se abriría paso la crisis y el enfrentamiento que inundaría todos los aspectos de la vida. Sin embargo, lo que intenta mostrar la autora es que en realidad no existían tales contrastes. Para ello propone trabajar los diversos temas de la vida cotidiana como un todo, y no separarlo en décadas. Dice:

[...] esta representación tradicional y hegemónica es menos definida cuando miramos el período desde otro ángulo: el de la vida cotidiana. La aparente homogeneidad interna de ambas décadas, o su tajante separación resulta difusa. Al explorar lo cotidiano se desdibujan sus límites y emerge una fase larga, en la que las transformaciones en la vida diaria se procesan progresivamente. $y$ otra, en las que se aceleran (p. 10).

La autora entiende que, en cambio, se perciben unos "Iargos cincuenta" que llegarían hasta 1967, año en el que comenzaría otro período que abarcaría hasta el golpe de Estado, llamado "sexenio crítico", caracterizado por el aumento de la conflictividad en materia política, social y cultural; y modificaciones importantes en la vida diaria que culminarían con el control y reglamentación de la vida cotidiana marcada por el nuevo gobierno de facto. El libro consta de dos partes, la primera consta de doce capítulos mientras que la segunda de tan solo seis. Se incluye, además, en este tomo que consta de 383 páginas, un prólogo escrito por la misma autora, un anexo donde se pasa revista en forma cronológica a los principales hechos de violencia entre 1967 y 1972, y una extensa bibliografía.

En la primera parte, encontramos una detallada descripción del cambio escénico de la ciudad, con la gran cantidad de nuevas construcciones arquitectónicas y monumentales (que al día de hoy pasaron a ser características), los cambios en la iluminación de las calles, los ruidos, los olores de los grandes basurales, los conflictos por la falta de agua, la desarticulación de los barrios, entre otras cosas que no son sometidas a nivel alguno de análisis.

La descripción comienza con la enumeración de los nuevos edificios como: el Zoológico, el Viaducto, el Hospital de Clínicas, el Panamericano, el Planetario; y algunos monumentos como "La diligencia" y "El Entrevero" de José Belloni.

La ciudad crecía; ya que la concentración de habitantes pasó a ser más numerosa, nuevos problemas aparecieron, como en el caso del transporte. Los tranvías, cada vez más viejos y deteriorados, pasaron a ser sustituidos por los nuevos trolleybuses, que, a partir de 1951, sugieren ser la solución al flujo cada vez más importante que miles de trabajadores en las horas pico generaban, sin embargo, nada pareció mejorar. Los problemas persistían: fallas en el servicio nocturno, unidades que se rompían y tardaban en ser reparadas, cantidad de coches insuficientes, paros en el transporte que dejaban a pie a media población; muestran que no todo era perfecto en "el país modelo". Además, consta destacar el aumento del mercado automotriz con gran cantidad de nuevos automóviles y motocicletas, que hicieron más difícil el tránsito, por lo que la Intendencia de Montevideo tuvo que instalar por primera vez los semáforos y "cebras" para que el número de accidentes, que hacia 1960 ascendía a 86 por día, pudiera disminuir.

Claro que los problemas experimentados durante los cincuenta, para el lector actual, no parecen ser muy alejados en el tiempo. La autora pretende demostrar que muchas de las expresiones de descontento y tópicos discutidos por la opinión pública bien podrían representar cuestiones contemporáneas, como es el caso de la gran cantidad de ruidos que la capital generaba con el transporte público, sus frenadas, bocinas, motocicletas con falta de caño de escape y demás dificultades.

Otro de los problemas que aquejaba a los montevideanos era la vivienda. Durante los cincuenta, la construcción tuvo un momento de auge con el desarrollo de la zona costera, donde los cada día más numerosos integrantes de las clases medias procuraban un departamento frente a la rambla. En cambio, la ciudad fue también testigo de la formación de los primeros cantegriles ubicados en la periferia de la capital, donde los sectores sociales más carenciados encontraron allí sus precarias viviendas construidas con materiales de desecho, postal que hasta el día de hoy se mantiene.

Haciendo referencia al subtítulo ("Sombras sobre el país modelo"), en cada uno de los capítulos se van mostrando los avances del país, y a su vez, los conflictos y problemas que se van a desarrollar a finales de los sesenta. Por ejemplo, 
la historiadora remarca que, durante los "largos cincuenta", la oferta y demanda de productos de confort para el hogar aumentó radicalmente debido al cambio de producción industrial que Estados Unidos tuvo que hacer, una vez culminada la Segunda Guerra Mundial y el conflicto en Corea. Sin embargo, mientras las demandas en el sector de los bienes de consumo eran satisfechas, uno de los principales productos de exportación de nuestro país, la carne, escaseó, debido al fuerte desabastecimiento provocado por el Frigorífico Nacional, que tenía el monopolio en Montevideo. Las vedas de carne provocaron largas colas en las carniceras de nuestro país, y se convirtió lentamente en un grave problema estructural, permitiendo la aparición y desarrollo de los mataderos clandestinos.

Existe un muy corto capítulo sobre el universo femenino, donde simplemente se destacan los nuevos cuidados de la belleza inspirados por las revistas femeninas y los programas de radio y televisión. Sin embargo, es extensa la sección sobre el ocio de los uruguayos, donde se popularizan la música rock y el cine con cada día más espectadores, el teatro, los deportes (sobre todo el fútbol), las vacaciones de verano y turismo a los distintos balnearios, el comienzo de la televisión; así como la supervivencia del tango y otras expresiones culturales que empiezan a ser desplazadas.

Uno de los capítulos más variopintos del libro es el llamado "Catástrofes, miedos y quimeras", que trata de estudiar los hechos y recelos que marcaron la memoria de las generaciones contemporáneas. Las distintas epidemias de poliomielitis que sacudieron a la población, como a comienzos del siglo XX lo había sido la tuberculosis, se constituyó en uno de los miedos más temidos. Esta enfermedad atacaba a los sectores más jóvenes y los dejaba postrados en sillas de ruedas para el resto de sus vidas. Dentro de las catástrofes más recordadas se mencionan las inundaciones de 1959, cuando, por más de trece días durante el mes de abril, no paró de llover, provocando miles de evacuados y grandes pérdidas materiales, así como la reacción del gobierno generando restricciones energéticas que afectaron a todo el país, y también pidiendo donaciones a los habitantes para ayudar a los damnificados.

Interesante es el guiño hacia la actualidad, en el apartado sobre los "infanto-juveniles", delincuentes menores de edad que supuestamente cometían todo tipo de delitos y a los que la población les temía. Resume Trochon sobre lo que la opinión pública manifestaba:
Cundió el convencimiento de que la colectividad carecía de instrumentos idóneos para rehabilitarlos, mientras algunas personas, urgidas por soluciones inmediatas, reclamaban mayor severidad, reduciendo la edad de imputabilidad. Para algunas personas todo lo que se hiciera era en vano [...] si las cosas seguían como hasta el momento, y en un futuro no muy lejano, los ciudadanos tendrían que pedir préstamos para ir armados como en la época del Far West ( $p$. 278).

Respecto al llamado "sexenio crítico", la autora propone centrarse en algunos puntos que entran en crisis, como la familia, la constante emigración de los habitantes, y un ambiente propicio para el desarrollo de otro tipos de expresiones como la canción de protesta, el resurgimiento del mercado editorial uruguayo y la llamada "revolución sexual".

Si bien estos años parecen ser los determinantes para comprender el posterior golpe de Estado en el Uruguay, Trochon se queda con breves descripciones y realmente deja el sabor a poco en cada uno de ellos. Los más extensos son los que se dedica al "boom" editorial en nuestro país, que se explica, según la autora, por el abaratamiento de las ediciones y el avance de la educación, provocando la publicación en 1968 de casi tres millones de ejemplares; y al "protagonismo de la violencia", donde se muestran las varias acciones de la guerrilla armada, la "rebelión" estudiantil, el accionar del aparato represivo del Estado y la mano dura del gobierno, para dejar asentado la caída de la democracia en 1973.

En definitiva, si bien el título hace referencia al Uruguay, en realidad, debería cambiársele por el de Montevideo, ya que la mayor parte de las referencias y de los capítulos estuvieron centrados en la capital. Por momentos, más que el análisis de la vida cotidiana, observamos una crónica de hechos y referencias que hacen ágil el texto, pero le quitan trascendencia. Además, la edición no está del todo cuidada, ya que presenta varios errores de tipeo durante toda la obra.

En cambio, podemos rescatar las imágenes seleccionadas que ilustran el relato que se construye, así como la gran cantidad (demasiados quizás) de recuadros con extractos de diarios de la época en referencia a los diversos tópicos que se desarrollan en la obra.

En conclusión, el trabajo de Trochon podemos catalogarlo de demasiado ambicioso para la gran cantidad de temas que quiso abordar, así como el corte cronológico extenso al que se dedicó. Lo más interesante puede ser el planteo 
de la nueva datación que el estudio de la vida cotidiana le permitió visualizar, al problematizar la dicotomía entre la década del 50 y la del 60 ,

como épocas de optimismo y pesimismo, auge y crisis, respectivamente. Sin embargo, deberían alentarse nuevos tipos de trabajos, con enfoques renovadores, que tan necesarios se hacen para nuestra historiografía actual.

Néstor Javier Gutiérrez Yannotti Universidad de Montevideo 